Journal of Engineering and Applied Sciences 14 (Special Issue 6): 9491-9503, 2019

ISSN: 1816-949X

(c) Medwell Journals, 2019

\title{
Investigation of Antibacterial Activity and Cytotoxicity of ZnO Nanoparticles Synthesized by a Novel Biological Method
}

\author{
${ }^{1}$ Nada K. Abbas, ${ }^{2,3}$ Israa Al-Ogaidi, ${ }^{2}$ Shurooq S. Mahmood and ${ }^{4}$ Hamid N. Obied \\ ${ }^{1}$ Department of Physics, College of Science for Women, University of Baghdad, Baghdad, Iraq \\ ${ }^{2}$ Department of Biotechnology, College of Science, University of Baghdad, Baghdad, Iraq \\ ${ }^{3}$ Department of Chemistry and biochemistry, Fulbright College of Arts and Sciences, \\ University of Arkansas, Arkansas, USA \\ ${ }^{4}$ Department of Pharmacology, College of Medical, University of Babylon, Babylon, Iraq
}

\begin{abstract}
This study explains the biosynthesis, characterization, evaluation of the antibacterial activity and cytotoxicity of zinc oxide nanoparticles (ZnO NPs) prepared by a low-cost and simple procedure. Bio-inspired ZnO NPs were synthesized with the aid of a novel, non-toxic, ecofriendly biological material namely; Banana Peels Extract (BPE). Qualitative phytochemical screening of the aqueous fruit peels extract of banana revealed the presence of many phytocomponents in it. The structural, morphological and optical properties of the synthesized nanoparticles have been characterized by using UV-Vis spectrophotometer, XRD, FE-SEM with EDX analysis, AFM and FTIR. The synthesized ZnO NPs were characterized by a peak at $373 \mathrm{~nm}$ in the UV-Vis spectrum. The XRD of the sample revealed the hexagonal wurtzite structure with an average grain size $11.98 \mathrm{~nm}$. Particle shapes and sizes were determined by FE-SEM. Surface morphology of the sample was studied by AFM. The FT-IR confirmed the presence of functional groups of both leaf extract and ZnO NPs. The results showed the antibacterial activity of the $\mathrm{ZnO}$ NPs against Gram-positive bacteria (Staphylococcus aureus) and Gram-negative bacteria (Pseudomonas aeruginosa and Escherichia coli). The cytotoxicity of ZnO NPs was tested against vero101 normal cell line and skin A431 cancer cell line by Crystal violet (CV) assay. Banana peels mediated ZnO NPs showed no evidence of toxicity against normal cell line, the nanoparticles are biocompatible and are non-toxic and effective cytotoxic effect against cancer cell line. These results clearly support the benefits of using a biological method for synthesizing ZnO NPs with anticancer activities.
\end{abstract}

Keywords: Zinc oxide NPs, biosynthesis, banana peels extract (BPE), phytochemical, antibacterial, cytotoxicity

\section{INTRODUCTION}

In recent years, metal and metal oxide nanoparticles have been intensively studied. The nano-sized materials have been appealed considerable attention because of their peculiar physicochemical properties compared to the bulk materials. Now-a-days, there are plenty of opportunities to fully employ in modern clinical technology the novel concepts and phenomena that have appeared in Nanoparticles research field (Jayaseelan et al., 2012). Transition metal oxides have a wide range of applications as catalysts, sensors, superconductors, antimicrobial agents, etc. Researchers have extensively studied the role of noble metals such as gold and silver nanoparticles as antimicrobial agents (Vayssieres, 2004; Sanpui et al., 2008). Recently, the antimicrobial activity of nano-sized $\mathrm{ZnO}$ particles has attracted attention, (Azizi et al., 2013) since the small size (less than $100 \mathrm{~nm}$ ) and high surface to volume ratio of the nanoparticles allow for better interaction with bacteria (Saadat et al., 2013). Recent studies have shown that these nanoparticles have selective toxicity to bacteria and exhibit minimal effects on human cells (Nagarajan and Kuppusamy, 2013; Singh et al., 2012). Since, most of the $\mathrm{ZnO}$ nanoparticles are produced synthetically; it has certain advantages, compared to silver nanoparticles, such as lower cost and white appearance (Singh et al., 2012).

The $\mathrm{ZnO}$ has received more attention due to its unique morphology and dimension dependent properties. $\mathrm{ZnO}$ being a wide band gap semiconductor $(3.3 \mathrm{eV})$ has received more attention as it possesses a wide range of useful properties including electrical, chemical, optical and magnetic properties (Patil et al., 2013; Suwanboon et al., 2013). The $\mathrm{ZnO}$ has gained much importance as it can be applied in many applications such as for gas sensing, catalyst, for semiconductors, UV-shielding materials, nano generators, an antibacterial

Corresponding Author: Nada K. Abbas, Department of Physics, College of Science for Women, University of Baghdad, Baghdad, Iraq 
agent, cosmetics as well as medicinal applications (Li et al., 2002; Ann et al., 2014). In recent days controllable synthesis of $\mathrm{ZnO}$ nano-materials of desired size and shapes has been the subject of the investigation by researchers because it has been found that the properties of $\mathrm{ZnO}$ nanoparticles are size and morphology dependent. Several methods have been developed to synthesize $\mathrm{ZnO}$ nanoparticles such as precipitation, hydrothermal, combustion, sol-gel, chemical vapor deposition, spray pyrolysis, sonochemical (Suwanboon, 2008; Podrezova et al., 2013; Zak et al., 2013).

The biosynthesized $\mathrm{ZnO}$ nanoparticles are trusted to be friendly with environment, non-toxic, bio-safe and bio-compatible. It is desirable for biomedical application such as drug carriers, cosmetics and filling the medical materials (Lakshmeesha et al., 2014).

Plants and/or their extracts provide a biological synthesis route of several metallic nanoparticles which are more eco-friendly and allow controlling the synthesis with well-defined size and shape (Bar et al., 2009). The enzymes, (Prasad and Jha, 2009) plant leaf extract (Sangeetha et al., 2011) and bacteria (Jayaseelan et al., 2012) plays a vital role in the green synthesis of zinc oxide nanoparticles.

Based on the review of literature, the bio synthesis of ZnO NPs using various plants has been carried out, Cassia fistula plant extract (Suresh et al., 2015a) Trifolium pratense flower extract, (Dobrucka and Dlugaszewska, 2016) Aloe barbadensis miller leaf extract, (Sangeetha et al., 2011) Candida albicans, (Mashrai et al., 2017) Vitex negundo extract, (Ambika and Sundrarajan, 2015) leaf extract of Tamarindus indica (L.), (Elumalai et al., 2015a) Nephelium lappaceum L. peel extract (Yuvakkumar et al., 2014) Solanum nigrum leaf extract, (Ramesh et al., 2015) Azadirachta indica, (Bhuyan et al., 2015) curry leaf Murraya koenigii, (Elumalai et al., 2015b) Borassus flabellifer fruit extract, (Vimala et al., 2014) Artocarpus gomezianus fruits extract, (Suresh et al., 2015b) Ocimum basilicum L. var. purpurascens Benth.-Lamiaceae leaf extract (Salam et al., 2014) Moringa oleifera leaf extract (Elumalai et al., 2015c).

Banana is one of the most common crops grown in almost all tropical countries; therefore, it is an abundant and cheap agricultural product. Peels represent about 30-40 g/100 g of fruit weight (Pangnakorn, 2006). The banana peels waste is normally of disposed in municipal landfills, which contribute to the existing environmental problems. However, the problem can be recovered by utilizing its high-added value compounds, including the dietary fibre fraction that has great potential in the preparation of functional foods. Dietary fibre has shown beneficial effects in the prevention of several diseases, such as cardiovascular diseases, constipation, irritable colon, diverticulosis, colon cancer and diabetes (Rodriguez et al., 2006). The crude extract of this peel has anti-infection, anti-parasitic, anti-bacterial, anti-fungal and anti-inflammation activity (Van Beek et al., 1984; Pratchayasakul et al., 2008). Aqueous extract of banana peel has rich phytochemicals such as alkaloids, tannins, Flavonoids, phytosterols, phenols, terpenes and carbohydrates. Flavonoids are known to be synthesized by plants in response to microbial infections (Gopinath et al., 2011).

In this study, distilled water was used to obtain the peels extract of banana. The peels of these plants were qualitatively screened for phytochemicals using standard methods. The aim of the current study is to synthesize $\mathrm{ZnO}$ NPs through a green approach with the aid of a novel, non-toxic, eco-friendly biological material namely, abundantly available and as a waste; Banana Peels Extract (BPE) and the nanoparticles have been characterized utilizing UV-Visible spectroscopy, X-Ray diffraction (XRD), Field Emission Scanning Electron Microscopy (FE-SEM) with EDX analysis, Atomic Force Microscopy (AFM) and Fourier Transform Infrared Spectroscopy (FT-IR) analysis.

Besides, an application of these nanoparticles that are biologically synthesized as antibacterial against Gram-positive bacteria (Staphylococcus aureus) and Gram-negative bacteria (Pseudomonas aeruginosa and Escherichia coli) has also been investigated. Minimum inhibitory concentration (MIC) was determined by micro broth dilution technique. The potential toxicity of $\mathrm{ZnO}$ NPs against vero101 normal cell line and skin A431 cancer cell line was evaluated in this present work by Crystal violet (CV) assay.

\section{MATERIALS AND METHODS}

Preparation of Fresh Banana Peels Extract (BPE): Banana Peels Extract (BPE) was prepared according to Ibrahim (2015) with slight modification; which includes the use of microwave oven to cut short the time also to preserve the vital resources in the banana peels.

Qualitative phytochemical analysis of the peels extracts of banana: The qualitative phytochemical analysis of the banana peels extract as an aqueous extraction were done by using different phytochemical screening to distinguish the chemical components existent in the extract in comparison with standard chemical reagents.

Test for flavonoids: A mixture of $1 \mathrm{~mL}$ of the peels extract and $1 \mathrm{~mL}$ of $5 \%$ lead acetate in a test tube was allowed to stand at room temperature $\left(25^{\circ} \mathrm{C}\right)$ for $2 \mathrm{~min}$. Formation of white precipitate in the sample indicates that the extract contained flavonoids (Harborne, 1998; Trease and Evans, 1989). 
Test for tannins: A solution of $2 \mathrm{~mL}$ of peels extract was treated with $10 \%$ alcoholic ferric chloride. That observe of the formation of blue or green colour indicate to presence of tannins (Sasikumar et al., 2014).

Test for alkaloids: Mayer's reagent and Dragendorff's reagent were used in crude extract to test the presence of alkaloids. One milliliter of the peels extract was added with $5 \mathrm{~mL}$ of $1 \%$ hydrochloric acid, filtered and tested with the reagents. The formation of white or creamy precipitates was taken as a positive result for the presence of alkaloids (Harborne, 1998; Trease and Evans, 1989).

Test for saponins: A mixing of $2 \mathrm{~mL}$ of the extract and $6 \mathrm{~mL}$ of distilled water in a test tube was shaken vigorously and observed formation of persistent foam that indicated the presence of saponins (Trease and Evans, 1989).

Test for glycosides: A few drops of Keed reagent [3-5 dinitrobenzoic acid (0.5 g) dissolved in $25 \mathrm{~mL}$ of $95 \%$ methanol and a few drops of $1 \mathrm{~N} \mathrm{NaOH}$ solution was added to $5 \mathrm{~mL}$ of peels extract. A change in color of solution to blue indicated the presence of glycosides.

Test for phenols: Five milliliters of the extract was dissolved in distilled water which was added to $3 \mathrm{~mL}$ of solution of lead acetate at a concentration of $10 \%$. The formation of a dark green colour indicates the presence of phenolic compounds (Harborne, 1998; Trease and Evans, 1989).

Test for terpenoids: One milliliter of the peels extract was treated with $1 \mathrm{~mL}$ of chloroform and $1 \mathrm{~mL}$ of concentrated sulphuric acid was added to form a layer. A reddish brown colour indicates the presence of terpenoids.

Test for steroids: One $\mathrm{mL}$ of chloroform, few drops of concentrated $\mathrm{H}_{2} \mathrm{SO}_{4}$ and $1 \mathrm{~mL}$ acetic anhydride were added and mixed with $5 \mathrm{~mL}$ of the peels extract. The observe of formation of dark red colour which indicates the presence of steroids (Sasikumar et al., 2014).

Synthesis of the ZnO nanoparticles from BPE: Zinc nitrate (99\% purity), sodium hydroxide (pellet 0.99\%) and ethanol were used as the introductory material was supplied by Sigma-Aldrich chemicals. Zinc oxide nanoparticles were prepared by green synthesis method using zinc nitrate and sodium hydroxide precursors mediated Banana Peels Extract (BPE) as a reducing and capping agent. In this experiment, 0.02 M Zinc nitrate $\left(\mathrm{Zn}\left(\mathrm{NO}_{3}\right)_{2} \cdot 4 \mathrm{H}_{2} \mathrm{O}\right)$ was added to $300 \mathrm{~mL}$ of distilled water under constant stirring using a magnetic stirrer to completely dissolve the zinc nitrate. Aqueous peel extract of banana was introduced into the above solution after
$10 \mathrm{~min}$ stirring at $6 \mathrm{~mL}$. After $1 \mathrm{~h}$ to the same $2.0 \mathrm{M}$ aqueous solution of sodium hydroxide $(\mathrm{NaOH})$ was added to make pH 12 under high speed constant stirring, drop by drop (slowly for $15 \mathrm{~min}$ ) touching the walls of the vessel resulted in a pale white aqueous solution. The reaction mixture was kept for incubation in a microwave oven (700 W, $2.45 \mathrm{GHz}$ ) for $1 \mathrm{~min}$ under static conditions. This reaction was then placed in a magnetic stirrer for $2 \mathrm{~h}$. The beaker was sealed at this condition. After the completion of the reaction, the supernatant solution was separated carefully. The remaining solution was centrifuged at 10,000 rpm for $10 \mathrm{~min}$. The pale white precipitate was then taken out and washed 3 times with distilled water followed by ethanol to get free of the impurities and remove the byproducts which were bound with the nanoparticles. Then a pale white powder of $\mathrm{ZnO}$ nanoparticles was obtained after drying at $400^{\circ} \mathrm{C}$ in oven for $2 \mathrm{~h}$ (Fig. 1). During drying, $\mathrm{Zn}(\mathrm{OH})_{2}$ is completely converted in to $\mathrm{ZnO}$.
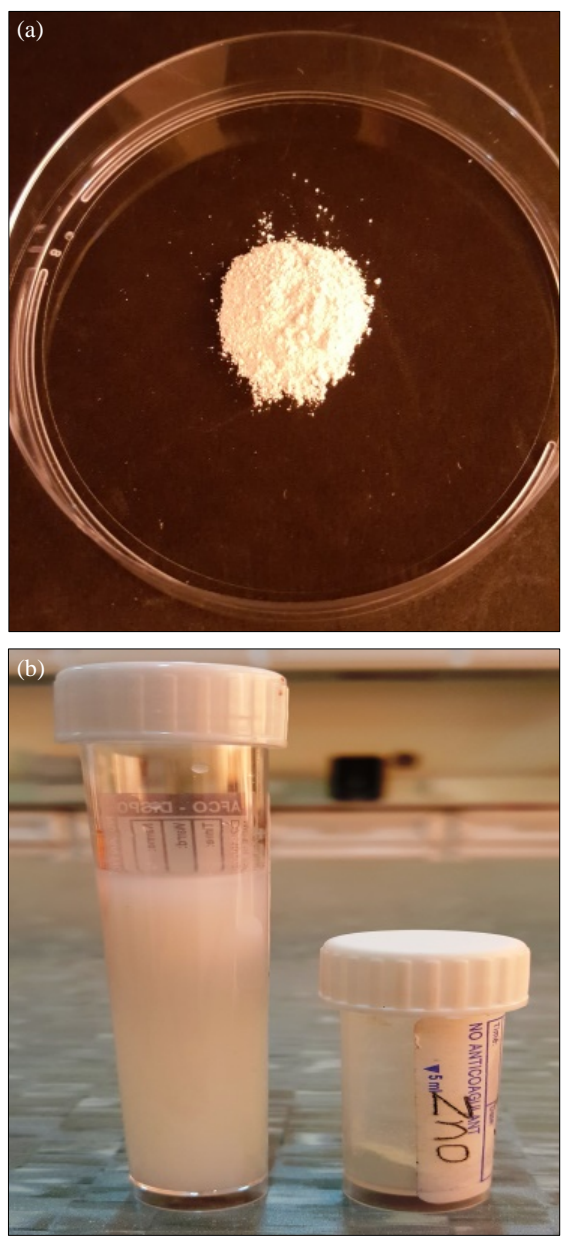

Fig. 1: ZnO nanoparticles and aqueous solution of $\mathrm{ZnO}$ nanoparticles 
Characterization of the ZnO nanoparticles: In order to study the structural properties of ZnO NPs, the crystalline structure was recorded by X-ray diffractometer (XRD-6000, Shimadzu, Japan), the source of radiation is $\mathrm{Cu}\left(\mathrm{k}_{\alpha}\right)$ with wavelength of $(\lambda=1.5405 \AA)$, voltage $60 \mathrm{kV}$ and current $80 \mathrm{~mA}$, at scanning speed of 5 degrees $\mathrm{min}^{-1}$ in $2 \theta$ range from $20-80^{\circ}$, these measurements were carried out on dried and finely grounded samples on Nano-Filter paper. The size and shape of the $\mathrm{ZnO}$ nanoparticles were determined by FE-SEM with EDX analysis and AFM. The morphology of synthesized ZnO NPs was observed by Field emission scanning electron microscopy (FE-SEM, SIGMA VP-500, ZEISS) and the elemental composition by recorded using (EDX, ZEISS). The surface morphology, particle size distribution and root mean square of roughness of the $\mathrm{ZnO}$ NPs were performed by using atomic force microscope AFM (AA3000 Scanning Probe Microscope SPM, tip NSC35/AIBS from Angstrom Advanced Inc., USA). The Ultraviolet-Visible spectra of the bioreduction ZnO NPs were monitored periodically as a function of wavelength within a range from 190-1100 nm by using UV-VIS Spectrophotometer (UV-1800 Shimadzu, Japan). The $\mathrm{UV}$-Vis spectra were monitored for the sample at a resolution of $1 \mathrm{~nm}$ at room temperature. In order to determine the functional groups which present in biomolecules in the plant extract surface and their possible involvement in the synthesis of $\mathrm{ZnO}$ nanoparticles, Fourier Transform Infrared (FTIR) Spectroscopy measurements was carried out. The test samples were independently dried and blended with $\mathrm{KBr}$ to obtain a pellet. The FTIR Spectrometer where detected by used (TENSOR 27, Bruker Optik GmbH, Germany) ranging from $400-4000 \mathrm{~cm}^{-1}$.

Activation and preparation of the bacterial isolates: The bacterial isolates used in this study were obtained from Department of Biotechnology, College of Science, University of Baghdad, they were Gram-positive bacteria (Staphylococcus aureus) and Gram-negative bacteria (Pseudomonas aeruginosa and Escherichia coli) were used to evaluate the antibacterial activity of prepared $\mathrm{ZnO}$ nanoparticles. Bacterial isolates were streaked on brain heart infusion agar and incubated for $18 \mathrm{~h}$ at 37 . Then single colony was picked up from media plate and inoculated into $5 \mathrm{~mL}$ of brain heart infusion broth then incubated for overnight at 37.

Determination of minimum inhibitory concentration and minimum bactericidal concentration (MIC/MBC) as an anti-bacterial activity of $\mathrm{ZnO}$ nanoparticle: The anti-bacterial activities of nano-sized zinc oxide were evaluated against Gram-positive bacteria (Staphylococcus aureus) and Gram-negative bacteria (Pseudomonas aeruginosa and Escherichia coli) by serial dilution method through the determination of the minimum inhibitory concentration (MIC and MBC) in the culture broth. The method of two fold serial dilutions (28) was used in this study for determination of the minimum inhibitory concentration (MIC) values, $1 \mathrm{~mL}$ of media was taken in a test tube, to which, $1 \mathrm{~mL}$ of test solution (200 $\mu \mathrm{g} \mathrm{mL}^{-1}$ ) was added, thereafter, $0.1 \mathrm{~mL}$ of the bacterial strains prepared in $0.9 \% \mathrm{NaCl}$ was added to the test tube containing media and test solution. Serial dilution was done nine times giving concentrations of 200, 100, 50, 25, 12.5, 6.2, 3.1, 1.5 and $0.7 \mu g \mathrm{~mL}^{-1}$ (Fig. 2). Then $1 \mathrm{~mL}$ of each serial nanoparticles were added to the set of tubes except for that tubes of control. All tubes which contained tested samples and controls were incubated for $24 \mathrm{~h}$ at $37^{\circ} \mathrm{C}$ with shaking $200 \mathrm{rpm}$. The MIC values were taken as the lowest concentration required to arrest the growth of the bacteria in the test tube after incubation (showed no turbidity) while the minimum bactericidal concentration (MBC) was determined by sub culturing $50 \mu \mathrm{L}$ from each test tube showing no apparent growth (clear), if there was no growth this concentration was taken as MBC. A sterile loop was used to inoculate and spread the solutions on Mueller Hinton Agar medium in Petri dishes. The Petri dishes were incubated at $37^{\circ} \mathrm{C}$ for $24 \mathrm{~h}$ at the same conditions. Petri dishes of $\mathrm{MBC}$ were compared with control.

Cell culture: Vero101 normal cell lines and skin A431 cancer cell lines were obtained from Cancer Research Lab., Department of Pharmacology, College of Medical, University of Babylon, Babylon, Iraq. It was grown in $25 \mathrm{~mL}$ culture flask with growth medium containing 10\% FBS and antibiotics, incubated at $37^{\circ} \mathrm{C}$.

Cytotoxicity assays: The cytotoxicity assays were applied for determining the effect of $\mathrm{ZnO}$ NPs on Vero101 normal cell line and skin A431 cancer cell line culture, according to Freshney (1993). When the growth in the flask became as monolayer before it reached the exponential phase, the cell monolayer was harvested and re-suspended with a growth medium in a concentration of $5 \times 10^{5}$ cell $\mathrm{mL}^{-1}$ and seeded in each well of a 96-well microtiter plate and incubated for $24 \mathrm{~h}$ at $37^{\circ} \mathrm{C}$ in the incubator. Since the cell growth reaches $80 \%$, the wells were exposed to serial dilutions of the ZnO NPs. The cells were then exposed to $200 \mu \mathrm{L}$ of each of the serial dilutions of $\mathrm{ZnO}$ nanoparticles 200, 100, 50, 25, 12.5 and $6.2 \mu \mathrm{g} \mathrm{mL} \mathrm{mL}^{-1}$ and incubated for $48 \mathrm{hr}$ under similar conditions. Following incubation, the culture medium was changed and cells were incubated for another $24 \mathrm{~h}$. After the end of the exposure the wells washed with $200 \mu \mathrm{L}$ of a sterile Phosphate buffered saline (PBS). The effect of the ZnO NPs on the cell lines growth was assessed by Crystal violet (CV) assay. 

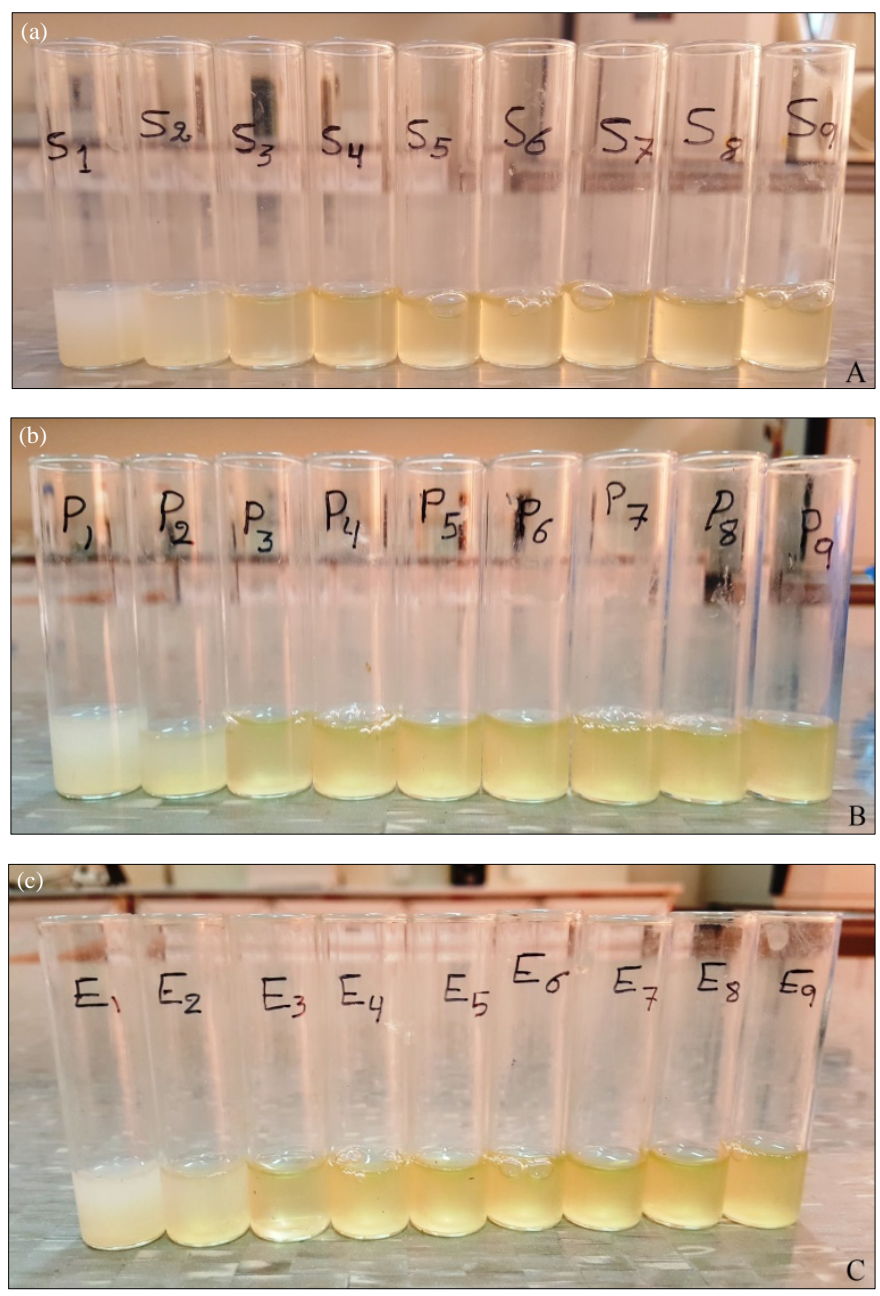

Fig. 2(a-c): Determination of minimum inhibitory concentration and minimum bactericidal concentration (MIC/MBC) as antibacterial activity of $\mathrm{ZnO}$ nanoparticle by serial dilution method against (a) Staphylococcus aureus, (b) Pseudomonas aeruginosa and (c) Escherichia coli

Crystal violet (CV) assay: Crystal violet (CV) assay was used to determine the optical density of the cell growth in each well of the microtiter plate, by using plate reader at $570 \mathrm{~nm}$. After the end point of the cytotoxicity assay, the maintenance medium with the test substance was discarded out and the wells washed with $100 \mu \mathrm{L}$ of cold PBS by automatic pipette. Then the cell cultures were fixed with $10 \%$ buffered formalin for $20 \mathrm{~min}$ at room temperature. A fixative solution was discarded and $100 \mu \mathrm{L}$ of $0.1 \%$ aqueous $\mathrm{CV}$ solution was added to each well. The samples were incubated at room temperature for 20 min with gentle shaking. After that the plates were washed by submersion in flowing tap water until there is no diffusion of the crystal violet stain from the wells. The plates were allowed to dry in the air and $0.2 \%$ Triton $\mathrm{X}-100$ in water was added to each well and incubated for $30 \mathrm{~min}$ at room temperature with gentle shaking to dissolve the dye. Then, $100 \mathrm{~mL}$ from each well was transferred into a new 96-well microplate and the absorbance was read at $570 \mathrm{~nm}$ by a microplate reader (Castro-Garza et al., 2007).

The percentage of inhibition was calculated according to the following equation:

$$
\text { Inhibition (\%) }=\frac{\begin{array}{l}
\text { Optical density of control wells- } \\
\text { Optical density of test wells }
\end{array}}{\text { Optical density of control wells }} \times 100
$$

The percentage of viability was calculated according to the following equation:

$$
\text { Viability }(\%)=100-\frac{\text { Optical density of control wells- }}{\text { Optical density of test well }}
$$




\section{RESULTS AND DISCUSSION}

To the researchers' knowledge, this report has been the first one on the preparation of $\mathrm{ZnO}$ NPs by using banana peels to avoid toxicity problems without a probability of cytotoxicity for living tissues after penetrating the target tissues. Conversely, other kinds of chemical reducing agent materials such as ammonia $\left(\mathrm{NH}_{3}\right)$ can cause significant toxicity for normal tissues. Interestingly the prepared ZnO NPs has selectivity toxic effect to the cancer cell.

Phytochemical properties of Banana Peels Extract (BPE): The phytochemicals present in the banana peels were revealed by standard methods before using in $\mathrm{ZnO}$ nanoparticles synthesis. The results proved the qualitative presence of alkaloids, flavonoids, Tannins, saponins, glycosides, phenols and terpenoids whereas, Steroids was absence in the extract. These phytochemicals in banana peels served as reducing, stabilizing and capping agents for the microwave assisted synthesis of $\mathrm{ZnO}$ nanoparticles from $\mathrm{ZnNO}_{3}$. As illustrated in Table 1, the phytochemical screening of banana peels extract exhibited the presence a complex mixture of phytochemical components.

Ultraviolet-visible spectra analysis: Figure 3 exhibits the absorption spectrum of the bio-synthesized ZnO NPs with a strong absorption peak around $373 \mathrm{~nm}$. This result indicating that ZnO NPs displays exciton absorption at $373 \mathrm{~nm}$ due to their large exciton binding energy at room temperature. The wavelength of $373 \mathrm{~nm}$ absorption peak confirms the occurrence of blue-shifted absorption spectrum with respect to the bulk value $(377 \mathrm{~nm})$ of the $\mathrm{ZnO} \mathrm{NPs}$, due to the quantum confinement effect, which in a good agreement of the previous report (Elumalai et al., 2015c).
The energy band gap $\left(E_{g}\right)$ value of the sample was calculated using the equation (Bai et al., 2014):

$$
\mathrm{E}_{\mathrm{g}}=\mathrm{hc} / \lambda_{\mathrm{m}} \mathrm{eV}
$$

where, $\mathrm{h}$ is the planks constant, $\mathrm{c}$ is the speed of light and $\lambda_{\mathrm{m}}$ is the wavelength corresponding to the maximum wavelength.

The energy band gap $\left(E_{g}\right)$ of ZnO NPs was calculated to be $3.33 \mathrm{ev}$. The appearance of the sharp excitonic peak indicates the high crystalline quality of the grown nanostructures (Zhou et al., 2002).

$\mathrm{X}$-ray Diffraction (XRD) analysis: The XRD pattern of bio-synthesized $\mathrm{ZnO}$ nanoparticles from peels extract banana is shown in Fig. 4. The ZnO NPs diffraction peaks clearly indicate highly crystalline structure. The sharp and narrow diffraction peaks appearing at about $2 \theta$ of 31.95, 34.60, 36.42, 47.70, 56.75, 63.02, 66.62, 68.13 and 69.22 (deg) were assigned to $100,002,101,102,110$, 103, 200, 112 and $201 \mathrm{hkl}$ plane values of $\mathrm{ZnO}$ nanoparticles. The peak intensity profiles were confirmed the hexagonal wurtzite structure by comparison with the data from JCPDS card No. 89-7102. The XRD pattern obtained is consistent with earlier reports (Parthibana and Sundaramurthy, 2015; Chitra and Annadurai, 2013).

Table 1: Qualitative phytochemical analysis of peels extracts of banana Phytochemical Aqueous extract of banana peels

Flavonoids

Tannins

Alkaloids

Saponins

Glycosides

phenols

Steroids

Terpenoids

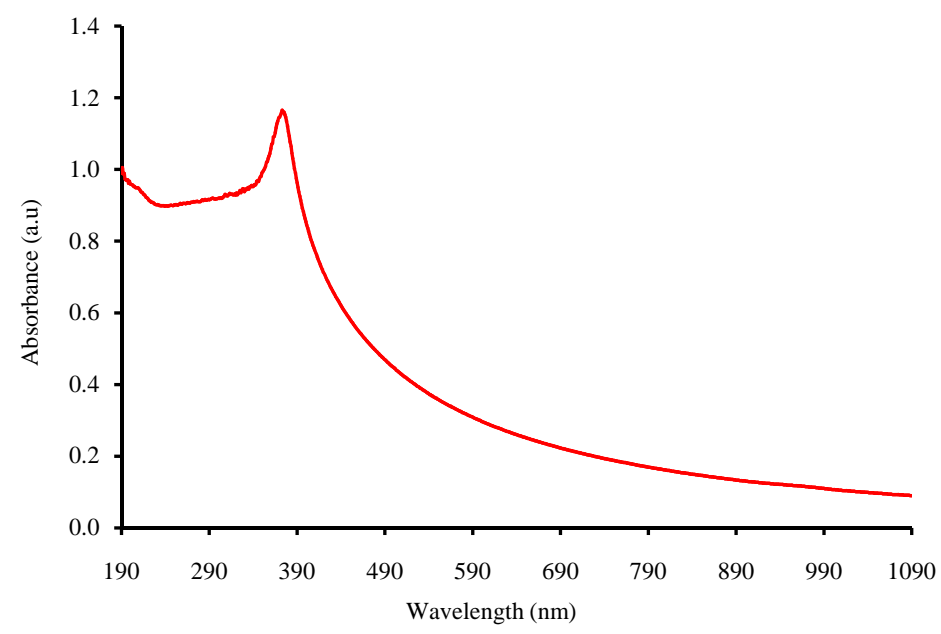

Fig. 3: UV-Vis spectrum of $\mathrm{ZnO}$ nanoparticles 


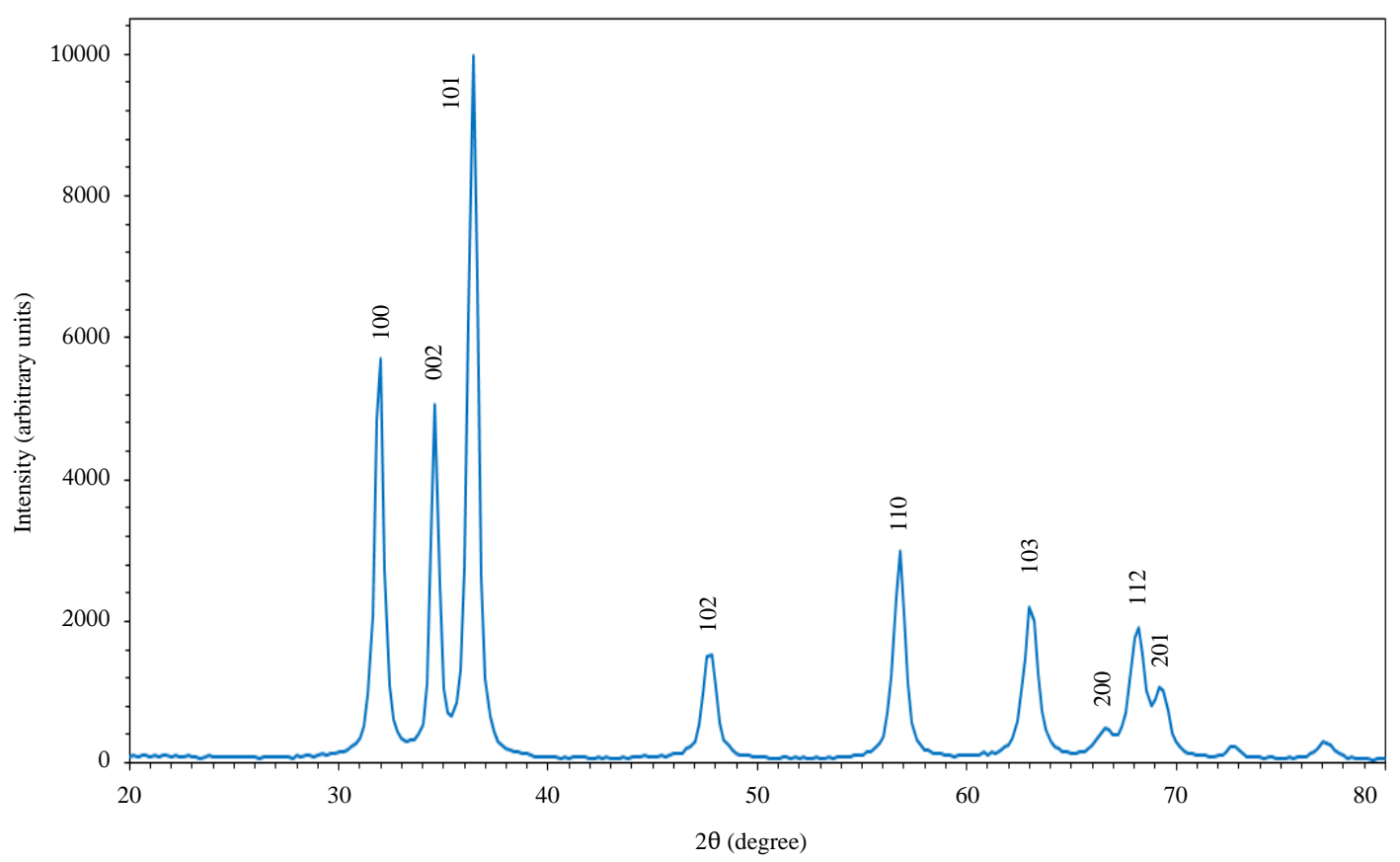

Fig. 4: XRD pattern of $\mathrm{ZnO}$ nanoparticles

Table 2: Structure and geometric parameters of $\mathrm{ZnO}$

\begin{tabular}{lccc}
\hline $2 \theta\left(^{\circ}\right)$ & d-spacing $(\AA)$ & FWHM $(\beta)$ & Grain size $(\mathrm{nm})$ \\
\hline 31.9537 & 2.798 & 0.6320 & 13.076 \\
34.6051 & 2.589 & 0.5900 & 14.104 \\
36.4245 & 2.464 & 0.6288 & 13.301 \\
47.7053 & 1.904 & 0.7890 & 11.009 \\
56.7595 & 1.620 & 0.7132 & 12.660 \\
63.0208 & 1.473 & 0.7724 & 12.063 \\
66.6222 & 1.402 & 1.0000 & 9.505 \\
68.1318 & 1.375 & 0.8911 & 10.761 \\
69.2215 & 1.356 & 0.8466 & 11.400 \\
& & Average & 11.986 \\
\hline
\end{tabular}

The calculation of average grain size was attained by using Scherer's equation (Cullity, 1967):

$$
\mathrm{D}=\frac{\mathrm{K} \lambda}{\beta \cos \theta} \AA
$$

where, D is the average crystallite size in $\AA, K$ is the shape factor, $\lambda$ is the wavelength of $\mathrm{X}$-ray (1.5406 $\AA$ ) $\mathrm{Cu}-\mathrm{K} \alpha$ radiation, $\theta$ is the Bragg angle and $\beta$ is the corrected line broadening of the nanoparticles. The average powder particle size calculated by Scherer's equation was found to be $11.98 \mathrm{~nm}$. The calculated values are listed in Table 2.

FE-SEM with EDX analysis: After the substantiation of XRD result the sample was proceeded for the further FE-SEM with EDX studies. The size, shape and surface morphology of the $\mathrm{ZnO}$ nanoparticles are clearly indicated FE-SEM image as shown in Fig. 5a, the micrograph images of $\mathrm{ZnO}$ nanoparticles prove that they have granular nano-sized range and have a uniform distribution with agglomerated particles of spherical shape (Elumalai et al., 2015c). The particle size ranges from 10-24 nm as shown in Fig. 5a. Energy Dispersive X-ray (EDX) spectrometer analysis is confirmatory presence of elemental zinc and oxygen signals of the ZnO NPs. The vertical axis displays the number of $\mathrm{x}$-ray counts although the horizontal axis displays energy in $\mathrm{KeV}$ (Fig. 5b). The weight and the atomic percentage of zinc, oxygen was found to be 77.9 and 22.1 these corresponds, the spectrum without impurities peaks.

Atomic Force Microscopy (AFM) analysis: The AFM images were used to characterize the structure morphology and size of the ZnO NPs. Figure 6 showed lateral and 3D AFM image for the biosynthesis $\mathrm{ZnO}$ nanoparticle. From AFM pictures we can see that the size of nanoparticles is bigger. The sizes of nanoparticles obtained from the AFM images appear bigger than the values that we get from XRD and FE-SEM measurements. We interpret those results to several reasons; first explanation relates the $\mathrm{ZnO}$ nanoparticles tend to form aggregates on the surface during deposition. Second explanation related to the shape of the tip AFM may cause misleading cross sectional views of the sample (Moosa et al., 2015; Delay et al., 2011). So, the width of the nanoparticle depends on probe shape. The resultant images for ZnO NPs were showed have spherical shape. The particle size of the ZnO NPs was found to be $51 \mathrm{~nm}$ and is also used to verify that the $\mathrm{ZnO}$ NPs were more or less homogenous in size. 

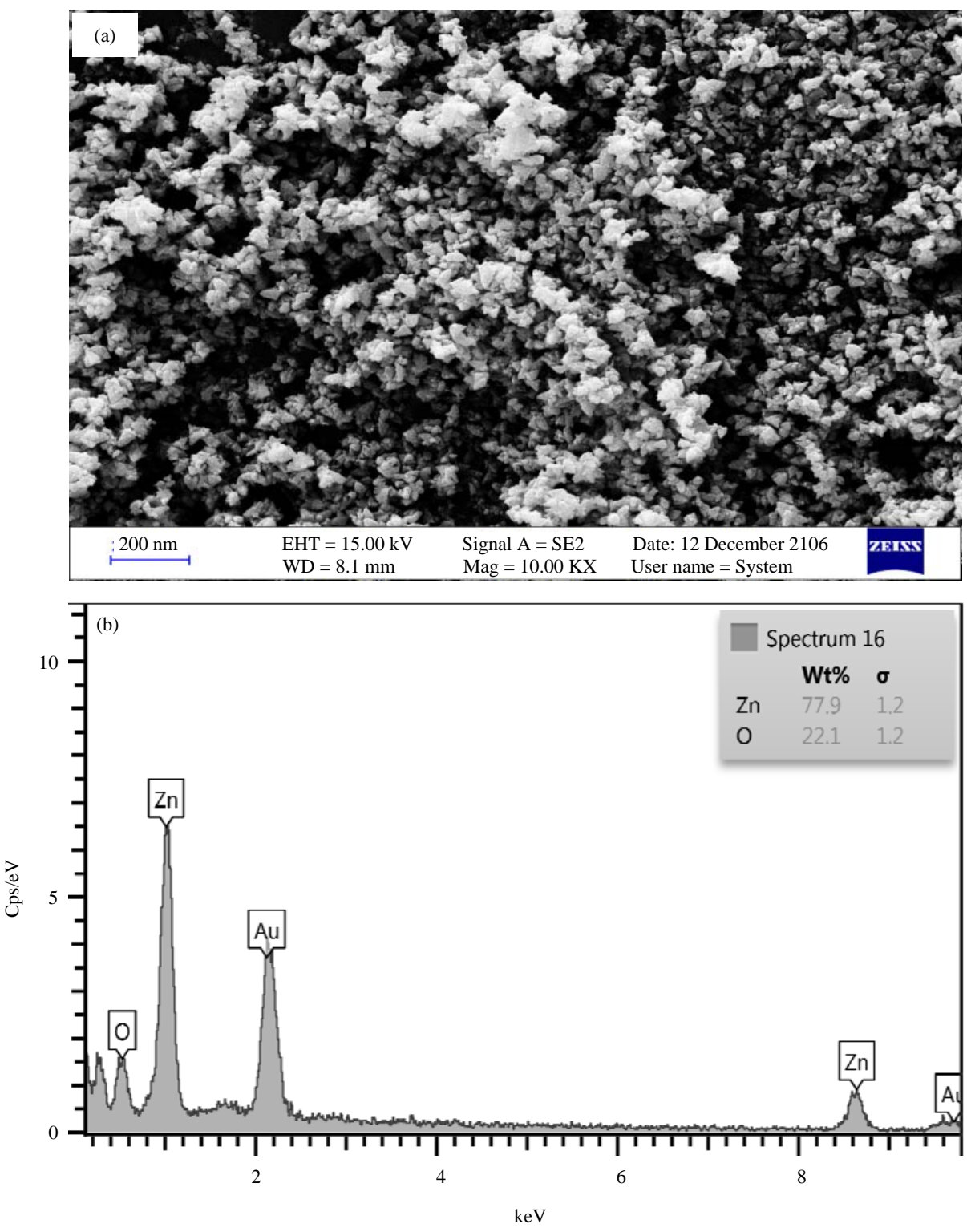

Fig. 5(a-b): (a) FE-SEM image of synthesized ZnO nanoparticles and (b) EDX spectrum

Fourier Transform Infrared Spectroscopy (FTIR): Figure 7 presents the FTIR spectra of bio-synthesis $\mathrm{ZnO}$ NPs and banana peel extract, which showed the composition and quality of the product. The absorption bands at 3427, 2928, 2354, 1605, 1408, 1056 and $524 \mathrm{~cm}^{-1}$ in banana peel extract wound be shifted into 3442, 2945, 2309, 1516, 1410, 1099 and $436 \mathrm{~cm}^{-1}$ of synthesized ZnO NPs sample. The strong absorption peak at $436 \mathrm{~cm}^{-1}$ correspond to the Zn-O bonding and confirm the presence of $\mathrm{ZnO}$ particles (Hong et al., 2009; Umar et al., 2009). The band observed at the region of $3442 \mathrm{~cm}^{-1}$ may be due to O-H stretching and deforming, probably due to atmospheric moisture. The other bands at 582 and $765 \mathrm{~cm}^{-1}$ were probably due to the carbonate moieties that are generally observed when FTIR samples are measured in air (Padmavathy and Vijayaraghavan, 2008). The absorption band near 1410-1516 $\mathrm{cm}^{-1}$ were due to $\mathrm{C}=\mathrm{O}$ stretching mode and the band near $2309 \mathrm{~cm}^{-1}$ was due to absorption of atmospheric $\mathrm{CO}_{2}$ on the metallic cations.

Determination of Minimum inhibitory concentration and minimum bactericidal concentration (MIC/MBC) as antibacterial activity of $\mathrm{ZnO}$ nanoparticle: In this study, the relative antibacterial activities of $\mathrm{ZnO}$ NPs suspensions against pathogenic isolates (Staphylococcus aureus, Pseudomonas aeruginosa and Escherichia coli) were studied in nutrient broth 

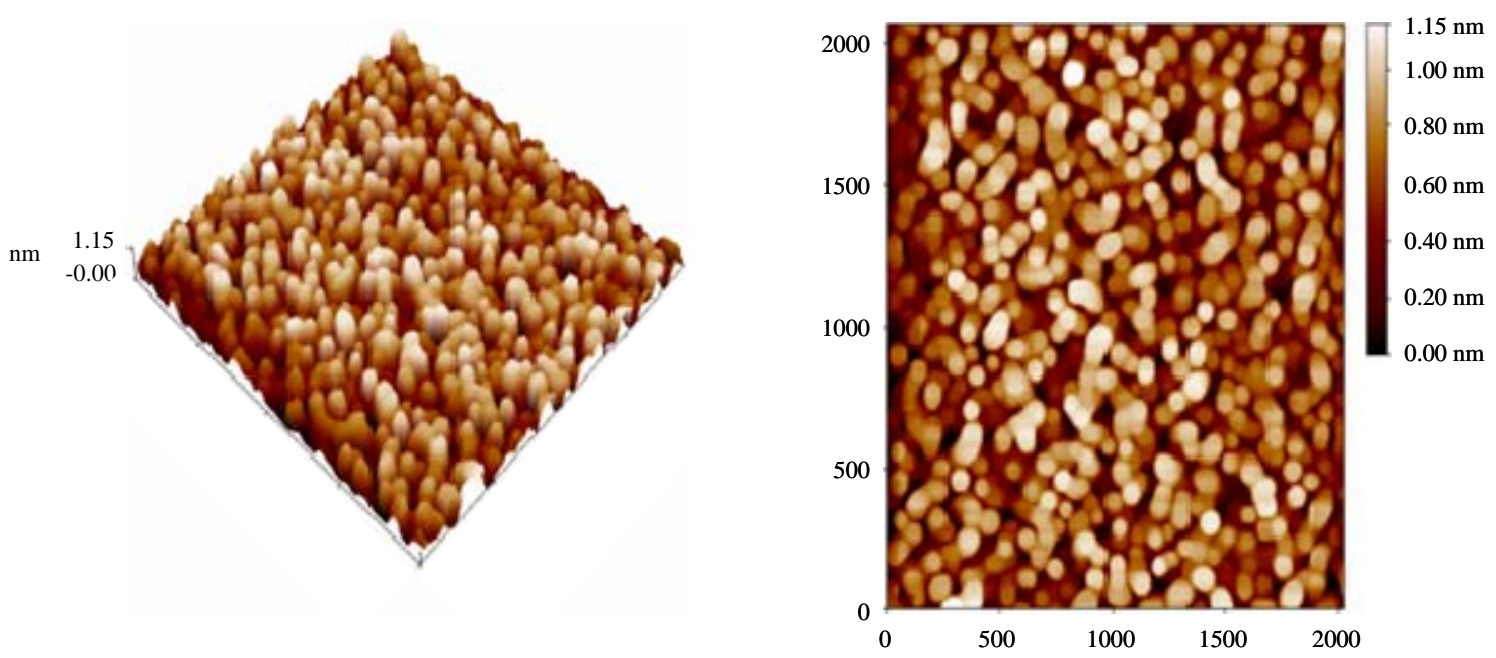

Fig. 6: Atomic force microscopy images show the particle size distribution of $\mathrm{ZnO}$ nanoparticles

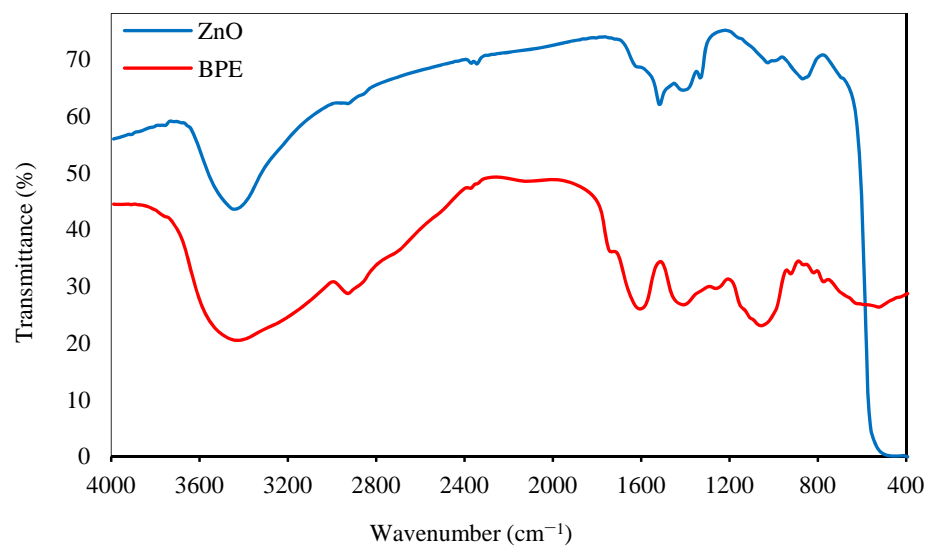

Fig. 7: FT-IR spectra of peels extract of banana and green synthesized $\mathrm{ZnO}$ nanoparticles

Table 3: Antibacterial activity MIC/MBC $\left(\mu \mathrm{g} \mathrm{mL}^{-1}\right)$ of $\mathrm{ZnO}$ against different type from bacteria

\begin{tabular}{lccc}
\hline Antibacterial activity of ZnO NPs & Staphylococcus aureus & Escherichia coli & Pseudomonas aeruginosa \\
\hline MIC & $\geq 6.2 \mu \mathrm{mL}^{-1}$ & $\geq 12.5 \mu \mathrm{gL}^{-1}$ & \\
MBC & $\geq 6.2 \mu \mathrm{g} \mathrm{mL}^{-1}$ & $\geq 12.5 \mu \mathrm{g} \mathrm{m}^{-1}$ & \\
\hline
\end{tabular}

quantitatively by determination of the MIC and MBC. Here, nine ZnO NPs suspensions with different concentrations were tested of 200, 100, 50, 25, 12.5, 6.2, 3.1, 1.5 and $0.7 \mu \mathrm{g} \mathrm{mL} \mathrm{m}^{-1}$ and the results are given in Table 3. The result showed that the Gram-negative bacterial isolates (Pseudomonas aeruginosa and Escherichia coli) were completely inhibited at the

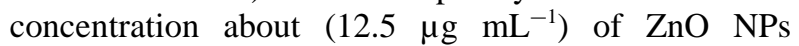
(Minimum inhibitory concentration MIC) but no significant antibacterial activity was observed at concentrations less than $\left(6.2 \mu \mathrm{g} \mathrm{mL}{ }^{-1}\right)$ of $\mathrm{ZnO} \mathrm{NPs}$, while that the Gram-positive bacterial isolates (Staphylococcus aureus) were completely inhibited at the concentration about $\left(6.2 \mu \mathrm{g} \mathrm{mL} \mathrm{m}^{-1}\right)$ of $\mathrm{ZnO} \mathrm{NPs}$ but no significant antibacterial activity was observed at concentrations less than $\left(3.1 \mu \mathrm{g} \mathrm{mL}^{-1}\right)$ of ZnO NPs. The result also showed that the minimum bactericidal concentration (MBC) was same as MIC for all isolates. Previously it has been reported that the antibacterial mechanism of nanoparticles against Gram-positive and Gram-negative bacteria relies on the difference in the cell-membrane structural composition, most distinctively peptidoglycan layer thickness (Shrivastava et al., 2007). Gram-positive bacteria possess thick peptidoglycan layer composed of linear polysaccharide chain cross-linked with small peptides, forming a rigid cell membrane to penetrate ZnO NPs, thus no inhibition zone was formed, whereas, the cell wall Gram-negative bacteria has thinner 
J. Eng. Applied Sci., 14 (Special Issue 6): 9491-9503, 2019

Table 4: LSD test to show the differences between control group and different treatment group

\begin{tabular}{llccccc}
\hline & & & & \multicolumn{2}{c}{$95 \%$ Confidence interval } \\
(I) croup & $(\mathrm{J})$ croup & Mean difference (I-J) & Std. Error & p-value & Lower bound & Upper bound \\
\hline Control & $6.25 \mu \mathrm{g}$ & $84.17325^{*}$ & 1.30837 & 0.000 & 81.3671 & 86.9794 \\
& $12.5 \mu \mathrm{g}$ & $87.30726^{*}$ & 1.30837 & 0.000 & 84.5011 & 90.1134 \\
& $25.0 \mu \mathrm{g}$ & $92.57240^{*}$ & 1.30837 & 0.000 & 89.7662 & 95.3786 \\
& $50.0 \mu \mathrm{g}$ & $93.10518^{*}$ & 1.30837 & 0.000 & 90.2990 & 95.9114 \\
& $100.0 \mu \mathrm{g}$ & $93.19920^{*}$ & 1.30837 & 0.000 & 90.3930 & 96.0054 \\
& $200.0 \mu \mathrm{g}$ & $96.55259^{*}$ & 1.30837 & 0.000 & 93.7464 & 99.3588 \\
\hline
\end{tabular}

*The mean difference is significant at the 0.05 level
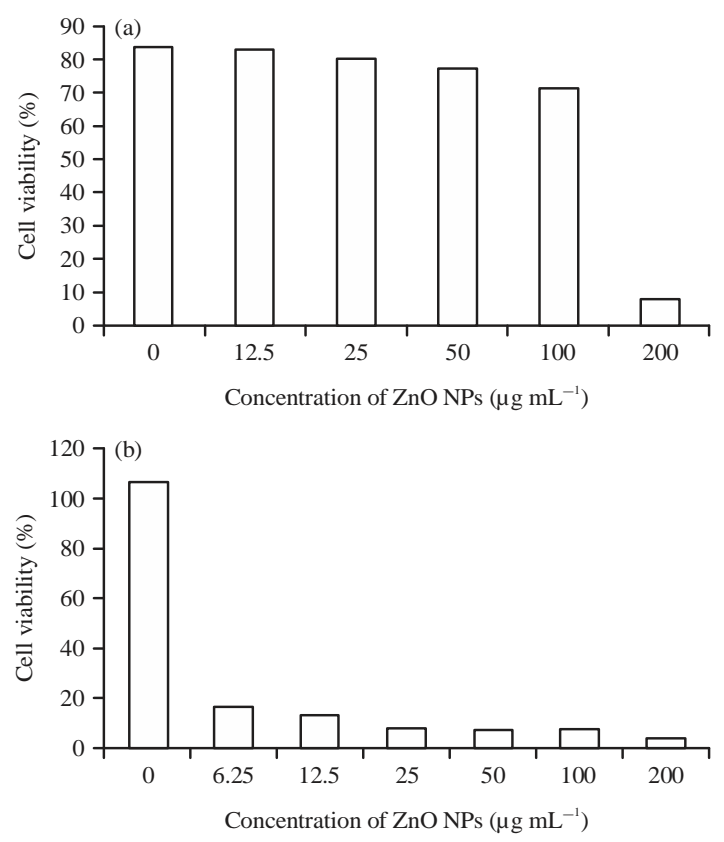

Fig. 8(a-b): Cytotoxic effect of $\mathrm{ZnO}$ nanoparticles against (a) Vero101 normal cell lines and (b) Skin A431 cancer cell lines. Cells were treated with various concentrations (200, $100,50,25$, 12.5 and $6.2 \mu \mathrm{gL}^{-1}$ ) of $\mathrm{ZnO}$ NPs for $72 \mathrm{~h}$ grown in a serum free media. The percentage of cell death induced was determined using the CV assay

polysaccharide layer, showed significant bactericidal effect. These results identical to the results of Padmavathy and Vijayaraghavan (2008) that ZnO nanoparticles have bactericidal activity in addition they interpreted in their study that once hydrogen peroxide is generated by $\mathrm{ZnO}$ nanoparticles, the nanoparticles remains in contact with the deadly bacteria to prevent further bacterial action and continue to generate and discharge hydrogen peroxide to the medium.

Assessment of cytotoxicity: The cytotoxicity of the zinc oxide nanoparticles was evaluated against Vero101 normal cell lines and Skin A431 cancer cell lines at various concentrations 200,100, 50, 25, 12.5 and $6.2 \mu \mathrm{g} \mathrm{mL}^{-1}$. Toxicity of ZnO NPs depends on multiple factors such as surface oxidation and the bioactivity of the outer coating, resulting in release of zinc ions and oxygen to the system leading to toxicity (Hoshino et al., 2004). Figure 8 shows the cell viability evaluated after $72 \mathrm{~h}$ exposure to ZnO NPs of various concentrations 200, 100, 50, 25, 12.5 and $6.2 \mu \mathrm{g} \mathrm{mL} \mathrm{m}^{-1}$. Vero101 normal cells exposed to $12.5-100 \mu \mathrm{g} \mathrm{mL}^{-1} \mathrm{ZnO}$ showed no evidence to the toxicity more than $72 \mathrm{~h}$ (Fig. 8a) and these results indicate that even at $100 \mu \mathrm{g} \mathrm{mL}^{-1} \mathrm{ZnO}$ the nanoparticles are non-toxic in vitro.

The ZnO NPs were selectively induced cytotoxicity on Skin A431 cancer cell lines in dose depended manner of ZnO NPs with a significant p value 0.05 (Table 4). Maximum concentration of zinc oxide nanoparticles ( $200 \mu \mathrm{g} \mathrm{mL}^{-1}$ ) effectively inhibited the growth of cell by more than $98 \%$ and these results indicate that even at $6.2 \mu \mathrm{g} \mathrm{mL}{ }^{-1} \mathrm{ZnO}$ the nanoparticles are toxic in vitro.

The toxicity mechanisms of ZnO NPs may be depend on the interaction between nanoparticles and biomolecules and toxicity mainly involves protein unfolding, (Chatterjee et al., 2010) fibrillation, thiol cross-linking and loss enzymatic activity. There are three mechanisms to explain why ZnO NPs exert toxic effects: oxidative stress, coordination effects and non-homeostasis effects (Chang et al., 2012). According to the previous report Guo et al. (2016) ZnO NPs induced increasing the level of hydrogen peroxide and hydroxyl radicals, decreased the level of molecular oxygen and glutathione and reduced interleukin-8 (IL-8) release (a signal for proinflammatory mediator release). This report can be explain our results which indicated that the bio-synthesized $\mathrm{ZnO}$ nanoparticles are non-toxic on human healthy cells at the highest concentration with $\mathrm{IC}_{50}=63.615 \mu \mathrm{g} \mathrm{mL}{ }^{-1}$ while it has toxicity on human cancer cells with least concentration with $\mathrm{IC}_{50}=31.122 \mu \mathrm{g} \mathrm{mL}^{-1}$ since the cancer cells already have high level of hydrogen peroxide and hydroxyl radicals (Guo et al., 2016). Therefor, bio-synthesized ZnO nanoparticles allowing them to be used as an alternative agent to chemical treatment that cause human cells damage. 


\section{CONCLUSION}

This study has reported the bio-synthesized of zinc oxide nanoparticles by using banana peels for the first time. It was cheap, simpler and better choice than physical and chemical methods as it is fast, clean and eco-friendly method. The XRD results indicated that the synthesized ZnO NPs have hexagonal wurtzite structure with the crystallite size of $11.98 \mathrm{~nm}$. The diffuse reflectance spectrum showed a sharp increase at $373 \mathrm{~nm}$ with the band gap energy value of $3.33 \mathrm{eV}$. The FTIR spectrum indicated the involvement of functional activities of peels extract in the reduction of ZnO NPs. The final preparation showed that zinc oxide nanoparticles had strong antibacterial activity with no cytotoxic effect on normal cell, whereas it showed anticancer activity in dose dependent manner. Therefore a major conclusion of this study which suggests that biologically synthesized $\mathrm{ZnO}$ NPs might be used as novel anticancer agents for the treatment of skin cancer.

\section{ACKNOWLEDGMENTS}

The authors wish to thank MSc Sarah Lafta Hamad, Department of Biotechnology, College of Science, University of Baghdad, Baghdad, Iraq, for providing the bacterial isolates. Authors are thankful to the Cancer Research Lab., Department of Pharmacology, College of Medical, University of Babylon, Babylon, Iraq, for providing the cell lines.

\section{REFERENCES}

Ambika, S. and M. Sundrarajan, 2015. Antibacterial behaviour of Vitex negundo extract assisted $\mathrm{ZnO}$ nanoparticles against pathogenic bacteria. J. Photochem. Photobiol. B: Biol., 146: 52-57.

Ann, L.C., S. Mahmud, S.K.M. Bakhori, A. Sirelkhatim and D. Mohamad et al., 2014. Antibacterial responses of zinc oxide structures against Staphylococcus aureus, Pseudomonas aeruginosa and Streptococcus pyogenes. Ceramics Int., 40: 2993-3001.

Azizi, S., M. Ahmad, M. Mahdavi and S. Abdolmohammadi, 2013. Preparation, characterization and antimicrobial activities of $\mathrm{ZnO}$ nanoparticles/cellulose nanocrystal nanocomposites. BioResources, 8: 1841-1851.

Bai, Z., X. Yan, X. Chen, K. Zhao, P. Lin and Y. Zhang, 2014. High sensitivity, fast speed and self-powered ultraviolet photodetectors based on $\mathrm{ZnO}$ micro/nanowire networks. Progress Nat. Sci.: Mater. Int., 24: 1-5.
Bar, H., D.K. Bhui, G.P. Sahoo, P. Sarkar, S. Pyne and A. Misra, 2009. Green synthesis of silver nanoparticles using seed extract of Jatropha curcas. Colloids Surf. Physicochem. Eng. Aspects, 348: 212-216.

Bhuyan, T., K. Mishra, M. Khanuja, R. Prasad and A. Varma, 2015. Biosynthesis of Zinc oxide nanoparticles from Azadirachta indica for antibacterial and photocatalytic applications. Mater. Sci. Semicond. Process., 32: 55-61.

Castro-Garza, J., H.B. Barrios-García, D.E. Cruz-Vega, S. Said-Fernández, P. Carranza-Rosales, C.A. Molina-Torres and L. Vera-Cabrera, 2007. Use of a colorimetric assay to measure differences in cytotoxicity of Mycobacterium tuberculosis strains. J. Med. Microbiol., 56: 733-737.

Chang, Y.N., M. Zhang, L. Xia, J. Zhang and G. Xing, 2012. The toxic effects and mechanisms of $\mathrm{CuO}$ and ZnO nanoparticles. Materials, 5: 2850-2871.

Chatterjee, T., S. Chakraborti, P. Joshi, S.P. Singh, V. Gupta and P. Chakrabarti, 2010. The effect of Zinc oxide nanoparticles on the structure of the periplasmic domain of the Vibrio cholerae ToxR protein. FEBS. J., 277: 4184-4194.

Chitra, K. and G. Annadurai, 2013. Antimicrobial activity of wet chemically engineered spherical shaped $\mathrm{ZnO}$ nanoparticles on food borne pathogen. Int. Food Res. J., 20: 59-64.

Cullity, B.D., 1967. Elements of X-Ray Diffraction. 3rd Edn., Addition-Wesley, Boston, Massachusetts, USA.

Delay, M., T. Dolt, A. Woellhaf, R. Sembritzki and F.H. Frimmel, 2011. Interactions and stability of silver nanoparticles in the aqueous phase: Influence of Natural Organic Matter (NOM) and ionic strength. J. Chromatogr. A., 1218: 4206-4212.

Dobrucka, R. and J. Dlugaszewska, 2016. Biosynthesis and antibacterial activity of $\mathrm{ZnO}$ nanoparticles using Trifolium pratense flower extract. Saudi J. Biol. Sci., 23: 517-523.

Elumalai, K., S. Velmurugan, S. Ravi, V. Kathiravan and S. Ashokkumar, 2015a. Bio-fabrication of Zinc oxide nanoparticles using leaf extract of curry leaf (Murraya koenigii) and its antimicrobial activities. Mater. Sci. Semicond. Process., 34: 365-372.

Elumalai, K., S. Velmurugan, S. Ravi, V. Kathiravan and S. Ashokkumar, 2015b. RETRACTED: Facile, eco-friendly and template free photosynthesis of cauliflower like $\mathrm{ZnO}$ nanoparticles using leaf extract of Tamarindus indica (L.) and its biological evolution of antibacterial and antifungal activities. Spectrochim. Acta Part A: Mol. Biomol. Spectrosc., 136: 1052-1057. 
Elumalai, K., S. Velmurugan, S. Ravi, V. Kathiravan and S. Ashokkumar, 2015c. RETRACTED: Green synthesis of Zinc oxide nanoparticles using Moringa oleifera leaf extract and evaluation of its antimicrobial activity. Spectrochim. Acta Part A. Mol. Biomol. Spectrosc., 143: 158-164.

Freshney, R.I., 1993. Culture of Animal Cells. 3rd Edn., Wiley, Hoboken, New Jersey, USA., ISBN: 9780471589662, Pages: 510.

Gopinath, S.M., T.B. Suneetha, V.D. Mruganka and S. Ananda, 2011. Evaluation of antibacterial activity of Tabernaemontana divaricata (L.) leaves against the causative organisms of bovine mastitis. Int. J. Res. Phytochem. Pharmacol., 1: 211-213.

Guo, D.D., Q. Li, H.Y. Tang, J. Su and H.S. Bi, 2016. Zinc oxide nanoparticles inhibit expression of manganese superoxide dismutase via amplification of oxidative stress, in murine photoreceptor cells. Cell Proliferation, 49: 386-394.

Harborne, J.B., 1998. Phytochemical Methods: A Guide to Modern Techniques of Plant Analysis. 3rd Edn., Chapman and Hall, London, UK., ISBN: 9780412572609, Pages: 302.

Hong, R.Y., J.H. Li, L.L. Chen, D.Q. Liu, H.Z. Li, Y. Zheng and J. Ding, 2009. Synthesis, surface modification and photocatalytic property of $\mathrm{ZnO}$ nanoparticles. Powder Technol., 189: 426-432.

Hoshino, A., K. Fujioka, T. Oku, M. Suga and Y.F. Sasaki et al., 2004. Physicochemical properties and cellular toxicity of nanocrystal quantum dots depend on their surface modification. Nano Lett., 4: 2163-2169.

Ibrahim, H.M.M., 2015. Green synthesis and characterization of silver nanoparticles using banana peel extract and their antimicrobial activity against representative microorganisms. J. Radiat. Res. Applied Sci., 8: 265-275.

Jayaseelan, C., A.A. Rahuman, A.V. Kirthi, S. Marimuthu and T. Santhoshkumar et al., 2012. Novel microbial route to synthesize $\mathrm{ZnO}$ nanoparticles using Aeromonas hydrophila and their activity against pathogenic bacteria and fungi. Spectrochim. Acta Part A: Mol. Biomol. Spectrosc., 90: 78-84.

Lakshmeesha, T.R., M.K. Sateesh, B.D. Prasad, S.C. Sharma, D. Kavyashree, M. Chandrasekhar and H. Nagabhushana, 2014. Reactivity of crystalline $\mathrm{ZnO}$ superstructures against fungi and bacterial pathogens: Synthesized using Nerium oleander leaf extract. Crystal Growth Design, 14: 4068-4079.

Li, R., S. Yabe, M. Yamashita, S. Momose, S. Yoshida, S. Yin and T. Sato, 2002. Synthesis and UV-shielding properties of $\mathrm{ZnO}$ - and $\mathrm{CaO}$-doped $\mathrm{CeO}_{2}$ via soft solution chemical process. Solid State Ionics, 151: 235-241.
Mashrai, A., H. Khanam and R.N. Aljawfi, 2017. Biological synthesis of $\mathrm{ZnO}$ nanoparticles using C. albicans and studying their catalytic performance in the synthesis of steroidal pyrazolines. Arabian J. Chem., 10: S1530-S1536.

Moosa, A.A., A.M. Ridha and M.H. Allawi, 2015. Green synthesis of silver nanoparticles using spent tea leaves extract with atomic force microscopy. Int. J. Curr. Eng. Technol., 5: 3233-3241.

Nagarajan, S. and K.A. Kuppusamy, 2013. Extracellular synthesis of zinc oxide nanoparticle using seaweeds of gulf of Mannar, India. J. Nanobiotechnol., Vol. 11. 10.1186/1477-3155-11-39.

Padmavathy, N. and R. Vijayaraghavan, 2008. Enhanced bioactivity of $\mathrm{ZnO}$ nanoparticles-an antimicrobial study. Sci. Technol. Adv. Mater., Vol. 9, No. 3. 10.1088/1468-6996/9/3/035004.

Pangnakorn, U., 2006. Valuable added the agricultural waste for farmers using in organic farming groups in Phitsanulok, Thailand. Proceedings of the Tropentag 2006 International Conference on Prosperity and Poverty in a Globalized World-Challenges for Agricultural Research, October, 11-13, 2006, University of Born, Bonn, Germany, pp: 275-278.

Parthibana, C. and N. Sundaramurthy, 2015. Biosynthesis, characterization of $\mathrm{ZnO}$ nanoparticles by using Pyrus pyrifolia leaf extract and their photocatalytic activity. Int. J. Innovative Res. Sci. Eng. Technol., 4: 9710-9718.

Patil, S.K., S.S. Shinde and K.Y. Rajpure, 2013. Physical properties of spray deposited Ni-doped Zinc oxide thin films. Ceram. Int., 39: 3901-3907.

Podrezova, L.V., S. Porro, V. Cauda, M. Fontana and G. Cicero, 2013. Comparison between $\mathrm{ZnO}$ nanowires grown by chemical vapor deposition and hydrothermal synthesis. Applied Phys. A, 113: 623-632.

Prasad, K. and A.K. Jha, 2009. ZnO nanoparticles: Synthesis and adsorption study. Nat. Sci., 1: 129-135.

Pratchayasakul, W., A. Pongchaidecha, N. Chattipakorn and S. Chattipakorn, 2008. Ethnobotany and ethnopharmacology of Tabernaemontana divaricata. Indian J. Med. Res., 127: 317-335.

Ramesh, M., M. Anbuvannan and G. Viruthagiri, 2015. Green synthesis of $\mathrm{ZnO}$ nanoparticles using Solanum nigrum leaf extract and their antibacterial activity. Spectrochim. Acta Part A: Mol. Biomol. Spectrosc., 136: 864-870.

Rodriguez, R., A. Jimenez, J. Fernandez-Bolanos, R. Guillen and A. Heredia, 2006. Dietary fibre from vegetable products as source of functional ingredients. Trends Food Sci. Technol., 17: 3-15.

Saadat, M., S.R. Mohammadi and M. Eskandari, 2013. Evaluation of antibacterial activity of $\mathrm{ZnO}$ and $\mathrm{TiO}_{2}$ nanoparticles on planktonic and biofilm cells of Pseudomonas aeruginosa. Biosci. Biotechnol. Res. Asia, 10: 629-635. 
Salam, H.A., R. Sivaraj and R. Venckatesh, 2014. Green synthesis and characterization of Zinc oxide nanoparticles from Ocimum basilicum L. var. purpurascens Benth.-Lamiaceae leaf extract. Mater. Lett., 131: 16-18.

Sangeetha, G., S. Rajeshwari and R. Venckatesh, 2011. Green synthesis of zinc oxide nanoparticles by Aloe barbadensis miller leaf extract: Structure and optical properties. Mater. Res. Bull., 46: 2560-2566.

Sanpui, P., A. Murugadoss, P.V.D. Prasad, S.S. Ghosh and A. Chattopadhyay, 2008. The antibacterial properties of a novel chitosan-Ag-nanoparticle composite. Int. J. Food Microbiol., 124: 142-146.

Sasikumar, R., P. Balasubramanian, P. Govindaraj and T. Krishnaveni, 2014. Preliminary studies on phytochemicals and antimicrobial activity of solvent extracts of Coriandrum sativum L. roots (Coriander). J. Pharmacogn. Phytochem., 2: 74-78.

Shrivastava, S., T. Bera, A. Roy, G. Singh, P. Ramachandrarao and D. Dash, 2007. Characterization of enhanced antibacterial effects of novel silver nanoparticles. Nanotechnology, Vol. 18, No. 22. 10.1088/0957-4484/18/22/225103.

Singh, G., E.M. Joyce, J. Beddow and T.J. Mason, 2012. Evaluation of antibacterial activity of $\mathrm{ZnO}$ nanoparticles coated sonochemically onto textile fabrics. J. Microbiol. Biotechnol. Food Sci., 2: $106-120$.

Suresh, D., P.C. Nethravathi, H. Rajanaika, H. Nagabhushana and S.C. Sharma, 2015a. Green synthesis of multifunctional Zinc oxide ( $\mathrm{ZnO})$ nanoparticles using Cassia fistula plant extract and their photodegradative, antioxidant and antibacterial activities. Mater. Sci. Semicond. Process., 31: 446-454.

Suresh, D., R.M. Shobharani, P.C. Nethravathi, M.A.P. Kumar, H. Nagabhushana and S.C. Sharma, 2015b. Artocarpus gomezianus aided green synthesis of $\mathrm{ZnO}$ nanoparticles: Luminescence, photocatalytic and antioxidant properties. Spectrochim. Acta Part A: Mol. Biomol. Spectrosc., 141: 128-134.
Suwanboon, S., 2008. Structural and optical properties of nanocrystalline $\mathrm{ZnO}$ powder from sol-gel method. ScienceAsia, 34: 31-34.

Suwanboon, S., P. Amornpitoksuk, A. Sukolrat and N. Muensit, 2013. Optical and photocatalytic properties of La-doped $\mathrm{ZnO}$ nanoparticles prepared via precipitation and mechanical milling method. Ceram. Int., 39: 2811-2819.

Trease, G.E. and W.C. Evans, 1989. Pharmacognsy. 11th Edn., Macmillian Publishers, London, UK., pp: 35-38.

Umar, A., M.M. Rahman, M. Vaseem and Y.B. Hahn, 2009. Ultra-sensitive cholesterol biosensor based on low-temperature grown $\mathrm{ZnO}$ nanoparticles. Electrochem. Commun., 11: 118-121.

Van Beek, T.A., R. Verpoorte, A.B. Svendsen, A.J.M. Leeuwenberg and N.G. Bisset, 1984. Tabernaemontana L. (Apocynaceae): A review of its taxonomy, phytochemistry, ethnobotany and pharmacology. J. Ethnopharmacol., 10: 1-156.

Vayssieres, L., 2004. On the design of advanced metal oxide nanomaterials. Int. J. Nanotechnol., 1: 1-41.

Vimala, K., S. Shenbagamoorthy, P. Manickam, V. Srinivasan and K. Soundarapandian, 2014. Green synthesized doxorubicin loaded zinc oxide nanoparticles regulates the Bax and Bcl-2 expression in breast and colon carcinoma. Process Biochem., 49: 160-172.

Yuvakkumar, R., J. Suresh, A.J. Nathanael, M. Sundrarajan and S.I. Hong, 2014. Novel green synthetic strategy to prepare $\mathrm{ZnO}$ nanocrystals using rambutan (Nephelium lappaceum L.) peel extract and its antibacterial applications. Mater. Sci. Eng.: C, 41: 17-27.

Zak, A.K., W.H. Majid, H.Z. Wang, R. Yousefi, A.M. Golsheikh and Z.F. Ren, 2013. Sonochemical synthesis of hierarchical $\mathrm{ZnO}$ nanostructures. Ultrason. Sonochem., 20: 395-400.

Zhou, H., H. Alves, D.M. Hofmann, W. Kriegseis, B.K. Meyer, G. Kaczmarczyk and A. Hoffmann, 2002. Behind the weak excitonic emission of $\mathrm{ZnO}$ quantum dots: $\mathrm{ZnO} / \mathrm{Zn}(\mathrm{OH})_{2}$ core-shell structure. Applied Phys. Lett., 80: 210-212. 